\title{
REDES DE PESQUISA COMO PROPOSTA INTEGRADORA PARA A INTERNACIONALIZAÇÃO DO CONHECIMENTO EM CONTEXTOS EMERGENTES
}

\author{
MARÍlIA COSTA MOROSINI \\ Pontifícia Universidade Católica do Rio Grande do Sul (PUCRS), Porto Alegre, \\ Rio Grande do Sul, Brasil \\ EgESLAINE dE NEZ \\ Universidade Federal de Mato Grosso - Campus Universitário do Araguaia \\ (UFMT - CUA), Barra do Garças, Mato Grosso, Brasil
}

\begin{abstract}
RESUMO: Este estudo discute a relação entre redes de pesquisa, construção do conhecimento e formação de pesquisadores, com destaque para a internacionalização. Metodologicamente, a partir de um estado de conhecimento, realizou-se uma pesquisa documental (lattes) dos membros chave da Rede Sulbrasileira de Investigadores de Educação Superior (RIES). A análise dos dados baseou-se numa abordagem crítica do conteúdo. É conclusiva a afirmação de que a participação em redes de pesquisa potencializa a produção do conhecimento, além de gerar um acréscimo na qualidade das investigações, intensificando a experiência formativa dos pesquisadores. Também foi possível compreender que o conhecimento gerado pelas redes tem maior alcance quando produzido coletivamente e disseminado nas metaredes.
\end{abstract}

Palavras-chave: Educação Superior. Produção do conhecimento. Redes de pesquisa. Internacionalização.

INTRODUÇÃO

No contexto da sociedade do conhecimento, encontra-se a universidade brasileira, enraizada em situações que se concretizam na realidade sócio-econômica. Vivem, dessa forma, um momento de se (re)organizar, de acordo com os desafios abarcados pela globalização, com uma expansão acentuada em seus constitutivos (acadêmicos, docentes e instituições). Para Morosini (2017), a Educação Superior se volta à internacionalização, levando em consideração a complexidade do processo desencadeado pela forma de produção e circulação de mercadorias, que ultrapassa as fronteiras. 
É notório que a discussão sobre a 'Internacionalização da Educação Superior' decorre de iniciativas antigas. Um dos momentos expressivos aconteceu na segunda reunião dos 'Parceiros da Educação Superior', Paris+5, em (2003), com mais de 400 representantes de 120 países. Foi um dos mais importantes encontros que delimitou pontos referenciais da visão adotada pela Conferência Mundial de Educação. Morosini (2016) expõe que os estudos sobre 'Internacionalização da Educação Superior' refletem - momento de transição que caracteriza os contextos emergentes, que são configurações em construção na Educação Superior observadas em sociedades contemporâneas e que convivem em tensão com concepções refletoras de tendências históricas.

Nessa direção, para compreender a realidade na qual essa investigação está inserida, refletiu-se sobre o sentido da produção do conhecimento, em um país situado na América Latina, que possui limitações do ponto de vista econômico, político e social. Esse contexto é sobrepujado pelos percalços advindos da internacionalização do conhecimento que impõe regras e limites à esfera científico-tecnológica nas nações periféricas.

Um dos conceitos-chave desse contexto é a geopolítica do conhecimento e sua justificativa remete a três razões: entender a importância estratégica do conhecimento como base nas capacidades industrial, científica e tecnológica; verificar quais os principais elementos que credenciam alguns países a se comportarem como centrais; e, por fim, identificar o caráter estratégico dos fluxos globais de atores envolvidos nessa produção (LIMA e CONTEL, 2011).

Temáticas, como, por exemplo, a posição, o tamanho, os recursos e o peso demográfico dos países, são articuladas com o fator tecnológico, que, para Castells (2001), é o elemento de transformação do panorama mundial. A geopolítica do conhecimento não se manifesta apenas na distribuição desigual dos circuitos dinâmicos de produção, além das sedes das unidades. Também se dimensiona em seus aspectos ligados à socialização do conhecimento produzido nas universidades e centros de pesquisa (NEZ, 2014).

A relevância científica deste estudo é caracterizada quando não se pode deixar de compreender os grupos e redes de pesquisa como potencializadores da socialização do conhecimento que se abre por meio da geopolítica da produção mundial. Para isso, o artigo em questão se divide em três partes, além da introdução e das considerações finais. Na primeira, apresenta-se a metodologia, contemplando os procedimentos realizados; na segunda parte, o aporte teórico é identificado, oferecendo discussões sobre os grupos e redes de pesquisa; e, na terceira, as análises decorrentes das considerações sobre a temática refletida neste estudo são desveladas.

\section{Metodologia}

Nas últimas décadas, observa-se um esforço investigativo sobre a Educação Superior, a produção do conhecimento e a globalização. Tais pontos são acompanhados de embates sobre tensões e força estratégica da realidade brasileira. Objetiva-se, neste artigo, demonstrar como os grupos e/ou redes de pesquisa articulam os pesquisadores e 
potencializam a construção e socialização do conhecimento, além da formação dos pesquisadores.

Ressalta-se, todavia, que o objeto dessa pesquisa se constrói numa ruptura em relação ao saber imediato. Nez (2014) considera que qualquer construção na realidade não é definitiva e nem dogmática, embora deva ser sistemática e rigorosa. Sendo assim, a pesquisa é uma atividade que requer habilidades e conhecimentos que o pesquisador tem, além de pressupostos que orientem seu pensamento e norteiem sua abordagem.

Os procedimentos metodológicos para abordar essa investigação se apoiaram, num primeiro momento, numa revisão da literatura constitutiva de um estado de conhecimento, termo cunhado por Morosini (2006) e Franco (2011), que se caracteriza como uma produção acadêmica que sintetiza um dado número de estudos, selecionados sob critérios previamente estabelecidos de uma temática.

Paralelamente, foi realizada uma pesquisa documental dos currículos lattes dos membros participantes de uma rede de pesquisa sulbrasileira. Esse estudo é de natureza qualitativa e, para a análise dos dados, realizou-se uma abordagem de cunho interpretativo, por meio dos princípios da análise de conteúdo (BARDIN, 2009). Desse modo, a metodologia teve como fundamento uma pesquisa básica, com abordagem de análise dos dados qualitativa (BOGDAN e BIKLEN, 1994), com revisão bibliográfica e documental.

\section{GRUPOS E REDES DE PESQUISA}

A história da produção do conhecimento no Brasil pode ser retratada em quatro momentos distintos: nas pesquisas realizadas por profissionais estrangeiros; na criação dos institutos de pesquisa; no início da Pós-graduação Stricto Sensu - quando a pesquisa passa a realizar-se nas universidades; e, por fim, nas políticas desencadeadas pela Fundação Coordenação de Aperfeiçoamento de Pessoal de Ensino Superior (CAPES), na última década do século XX, que, segundo B|ianchetti e Machado (2012), consolida o Sistema de Pós-graduação no país.

Hoje, a Pós-graduação tem como eixo regulador e componente predominante a pesquisa. Os mestrados e os doutorados são os espaços em que se inicia o processo de formação do pesquisador (concepção de universidade inspirada no modelo humboldtiano), além de um local dedicado a reforçar a qualidade na/da educação (NEZ, 2014). A sociedade do conhecimento (DIDRIKSSON, 2008) determina e, de certo modo, até impõe que as redes de pesquisa sejam a estratégia para a produção de conhecimento.

Essas considerações indicam que a Pós-graduação disponibiliza qualificação, que, por sua vez, intensifica a pesquisa e, consecutivamente, produz conhecimento. Este estudo absorve essa intencionalidade e procura enfatizar que esse movimento é produzido a partir e por meio das redes de pesquisadores. Para Morosini (2017), a dinâmica do ato de pesquisar aponta para a necessidade de atuação em rede, pois o ambiente gerado pela sociedade do conhecimento remete a desafios constantes com relação à internacionalização da Educação Superior.

Uma das condições indispensáveis para o funcionamento dos programas de Pós-graduação brasileiros é a comprovação da existência de grupo de pesquisas consolidados na área de conhecimento. Nez (2014) esclarece que um programa de Pós- 
graduação deve ser concebido e organizado como lugar de produção e socialização do conhecimento, um centro de pesquisa onde se realiza sua construção sistemática e permanente.

A atividade de pesquisa tem como espaço privilegiado para sua realização o grupo de pesquisa. A produção científica, tecnológica e cultural demanda permanente intercâmbio e trabalho coletivo que é garantido na atuação em grupo e redes.

No Brasil, o Diretório dos Grupos de Pesquisa (DGPB) constitui-se no inventário dos grupos em atividade no País. Esse projeto foi desenvolvido pelo Conselho Nacional de Desenvolvimento Científico e Tecnológico (CNPq) em ação conjunta com o Ministério da Ciência e Tecnologia (MCT), além de constituir-se numa base de dados que contêm informações sobre os grupos de pesquisa atuantes. Os dados informam os recursos humanos, as linhas de pesquisa, a produção científica e tecnológica, além das parcerias estabelecidas. Com isso, é capaz de identificar os limites, os desafios e o perfil geral da atividade científico-tecnológica (DIRETÓRIO, 2018). O DGPB não apresenta um item separado que possa identificar as redes de pesquisa, sendo assim, encontram-se diluídas dentre os grupos e, em algumas situações, nem identificadas como redes. Desse modo, nem sempre é possível identificá-las e caracterizá-las devidamente, pois não há informações detalhadas sobre sua dimensão e existência. $O$ mesmo acontece com o lattes, o link que deveriam aparecer as redes de pesquisa não está funcionando adequadamente e não gera os dados relativos à essa categorização.

Um grupo de pesquisa é um conjunto de indivíduos organizados hierarquicamente, em torno de uma liderança onde existe envolvimento profissional permanente. Mocelin e Franco (2006) estabelecem que o grupo é o elemento organizador do diretório. Caracterizado como a unidade de produção constituída por pesquisadores, acadêmicos, bem como por bolsistas e técnicos. Menezes (2000) esclarece que a unidade de formação pós-graduada não é um doutor isolado, mas um grupo de pesquisadores que se consolida ao longo dos anos, além de incluir, entre seus participantes, não só docentes, mas também acadêmicos e colaboradores diversos.

Com relação aos grupos de pesquisa, segue a tabela 1, com base no censo e nas séries históricas organizadas pelo DGPB, que apresenta os grupos por região brasileira.

Tabela 1 - Distribuição dos grupos de pesquisa segundo a região geográfica

\begin{tabular}{|c|c|c|c|c|}
\hline \multirow{2}{*}{ REGIÃO } & \multicolumn{2}{|c|}{2000} & \multicolumn{2}{|c|}{2016} \\
\hline & GRUPOS & $\%$ & GRUPOS & $\%$ \\
\hline Sudeste & 6.733 & 57,3 & 16.009 & 42,5 \\
\hline Sul & 2.317 & 19,7 & 8.637 & 22,9 \\
\hline Nordeste & 1.720 & 14,6 & 7.713 & 20,5 \\
\hline Centro-Oeste & 636 & 5,4 & 2.899 & 7,7 \\
\hline Norte & 354 & 3,0 & 2.382 & 6,3 \\
\hline TOTAL & 11.760 & 100 & 37.640 & 100 \\
\hline
\end{tabular}

Fonte: DGPB (2020). 
Conforme o quantitativo apresentado na tabela, observa-se que a Região destaque é a Sudeste (42\%), seguida da Sul (22\%), e, em último lugar, a Região Norte, que representa $6 \%$ do total. O percentual da primeira e da segunda regiões somam mais da metade dos grupos existentes no país (64\%), as regiões norte e centro-oeste juntas representam 14\% dos grupos no Brasil. O mesmo movimento é perceptível em 2000, ou seja, não se modificou 16 anos depois no censo.

Outro número expressivo é o total de grupos que, em 2000, era de 11.760. Em 2016, alcançaram 37.640. As séries representativas do diretório identificam um processo gradativo de aumento de números de grupos de pesquisa no Brasil, sempre mantendo a diferenciação nas regiões, reflexo do crescimento e implantação dos programas de Pósgraduação, que tiveram início no Sudeste. Segundo Nez (2014), as universidades federais foram responsáveis pela maior parte dos programas do Rio de Janeiro e em Minas Gerais, enquanto o estado de São Paulo, através de uma instituição estadual, se incumbia de desenvolver os cursos naquela região.

Destaca-se que, ainda hoje, a região Sudeste mantém predomínio em número de instituições e programas de Pós-graduação, conforme censos MEC/CAPES. Essa situação se reflete na destinação de recursos em uma espiral regional concentradora em que mais apoio e cursos representam maior investimentos em pesquisa, que, por sua vez, geram mais fomento e mais articulações em redes de investigadores (NEZ, 2014).

A geopolítica do conhecimento, pressuposto teórico dessa análise, tem sido estudada por autores que enfatizam a importância estratégica da localização de cada região produtiva e o poder discursivo que possuem (LIMA e CONTEL, 2011). Essa abordagem foca a divisão internacional do trabalho acadêmico e sintetiza os aspectos ligados à manutenção do poder das nações ativas, por meio da Internacionalização da Educação Superior. Não só a polarização de fluxos globais revela esse posicionamento, como também a localização concentrada de universidades e de institutos de pesquisa em algumas regiões/países.

Essa distribuição representada na tabela 1, segundo a região geográfica, legitima o locus de produção do saber. Esse movimento é respaldado em circuitos de informação que são gerados a partir de locais onde estão instalados grandes conglomerados de ciência e tecnologia, caracterizando os centros geopolíticos de poder no Brasil. Especificamente na constituição de grupos de pesquisa, a predominância é das duas regiões sugeridas (NEZ, 2014).

Para contrabalancear esses centros geopolíticos constituídos, as parcerias em rede são fundamentais e geradores de interlocução entre os grupos e os pares. A realização das pesquisas interinstitucionais, ao invés de um trabalho individual, é a expressão de um contexto emergente. Os grupos passam cada vez mais a fazer sentido na construção do conhecimento, porque, como espaços de produção, possibilitam a aproximação dos indivíduos por temáticas que formam redes e ampliam os centros geopolíticos de produção do conhecimento, tanto no Brasil como no mundo.

Para Franco e Morosini (2001), pensar os grupos de pesquisa nessa perspectiva implica considerar os reflexos das atividades para formação dos novos pesquisadores. E, consecutivamente, proporcionar a criação de redes que interliguem os grupos isolados. Isso porque é no entrelaçamento dos indivíduos que se corporificam em grupos, que se concretizam os processos de integração das redes. 
As redes são, ao mesmo tempo, concentradoras, dispersoras e condutoras de forças centrípetas e centrífugas. Santos (2006) expõe que "o fato de que a rede é global e local, una e múltipla, estável e dinâmica, faz com que a sua realidade, vista num movimento de conjunto, revele a superposição de vários sistemas lógicos, a mistura de várias racionalidades" (p. 189).

Leite (2005) esclarece que se constroem e reconstroem em múltiplos arranjos, frágeis e efêmeros, aumentando sua capacidade de ser visível e de implantar-se em diferentes contextos, ampliando-se e desdobrando-se continuamente. Há, pois, uma polifonia de vozes formadas por múltiplos sujeitos, elementos esses considerados os constructos das redes.

No contexto internacional do Espaço de Encontro Latino-Americano e Caribenho de Educação Superior (ENLACES), as redes se constituem de organizações, instituições ou associações internacionais que formam um conjunto inter-relacionado entre si de maneira permanente, multidirecional, horizontal e autônoma. Pois, "elas buscam propósitos específicos e comuns se constituindo em exemplos de autoorganização, de caráter espontâneo e descentralizado" (ENLACES, 2012, p. 01).

São inúmeras as conceituações de redes, mas admite-se que grande parte se enquadra na matriz epistemológica da integração. A integração é uma ferramenta das políticas de desenvolvimento das universidades, como política institucional, e dos pesquisadores, pois permite sua inserção como protagonista do processo. Isso significa dizer o mesmo que participante da rede (NEZ, 2019). Para Sebastian (2005), é fundamental expandir o conhecimento e estimular a formação de redes de pesquisa sustentáveis e apoiar as que já existem, além de estabelecer parcerias institucionais nas áreas do conhecimento.

A Conferência Mundial de Educação Superior já havia destacado a fundamental importância da cooperação. Torres (2011) aponta que, nesse processo, há um destaque para o papel das redes internacionais e suas iniciativas conjuntas de pesquisa e de intercâmbio. A rede analisada nessa investigação é um espaço, dentre muitos, que tem a funcionalidade de integração dos pesquisadores e isso evidencia um dos critérios para sua escolha neste estudo.

Na perspectiva da América Latina e Caribe, Baranzeli e Morosini (2018) citam que:

[...] a Conferência Regional de Educação Superior para a América Latina e Caribe - CRES 2018 reafirmou os princípios da CRES anterior, de 2008, quanto a necessidade imprescindível do desenvolvimento de redes entre as nações do sul-sul como uma das formas de desenvolvimento da sociedade latino-americana e da superação dos impasses e de grandes diferenças sócio econômicas entre estratos sociais (BARANZELI e MOROSINI, 2018, p. 278).

Para o Brasil, no que toca aos grupos de pesquisa e instituições participantes, pode-se verificar informações detalhadas na tabela 2, que traz um recorte temporal de 993-2016 (último censo contabilizado pelo DGPB). 
Tabela 2 - Número de instituições, grupos e pesquisadores

\begin{tabular}{l|r|r|r|r|r}
\hline DIMENSÕES & \multicolumn{1}{|c|}{$\mathbf{1 9 9 3}$} & \multicolumn{1}{c|}{$\mathbf{2 0 0 0}$} & \multicolumn{1}{c|}{$\mathbf{2 0 0 8}$} & \multicolumn{1}{c}{$\mathbf{2 0 1 0}$} & \multicolumn{1}{c}{$\mathbf{2 0 1 6}$} \\
\hline Instituição & 99 & 224 & 422 & 452 & 531 \\
\hline Grupos & 4.402 & 11.760 & 22.797 & 27.523 & 37.640 \\
\hline Linhas de Pesquisa & Não informado & 38.126 & 86.075 & 106.715 & 147.392 \\
\hline
\end{tabular}

Fonte: DGPB (2019).

Lima e Leite (2012) consideram que as redes se formam no interior dos grupos de pesquisa quando há produção coletiva e que devem acontecer com pesquisadores de outras instituições. "São teias que se armam e desarmam, o que as difere dos grupos de pesquisa em si" (p. 134). Nessa direção, a tabela 2 evidencia que o acréscimo nos últimos anos de instituições participantes dos grupos de pesquisa possibilita a formação de redes de colaboração interinstitucionais, de coautorias, de citação, de orientação e de parcerias conjuntas.

Adverte-se com as informações coletadas pelo censo do DGPB que, de 1993 a 2016, o número de universidades quintuplicou, o que evidenciou o interesse das instituições que realizaram o credenciamento dos grupos nesse período, ou seja, de 99 saltaram para 531. Acompanhando esse movimento, o acréscimo das linhas de pesquisa que, no ano de 2000, era de 38.126, passou, em 2016, para 147.392.

Claro que a filiação dos docentes da Pós-graduação a grupos e redes de investigação é de fundamental importância e refletora desse acréscimo. Segundo Severino (2010), as agências de fomento da pesquisa têm prestigiado cada vez mais essa iniciativa de organização de projetos em grupos interinstitucionais.

Ramos (2009) complementa que os grupos passam cada vez mais a fazer sentido, porque "[...] como espaços de produção de pesquisa na universidade, possibilitam a aproximação dos indivíduos por temáticas, superando estruturas rígidas" (p. 29). Assim sendo, a realização de um trabalho compartilhado, ao invés do individual, concretizando as parcerias, principalmente na Pós-graduação, se configura como potenciais geradores de pesquisa no seio das instituições.

\section{ANALISANDO OS DADOS ENCONTRADOS NOS LATTES}

O objetivo dessa investigação buscou demonstrar como os grupos e redes articulam os pesquisadores e potencializam a construção do conhecimento nas universidades. Para isso, a pesquisa de campo analisou uma rede de pesquisa que possui destaque no Brasil: a Rede Sulbrasileira de Investigadores de Educação Superior (RIES). Considera-se, nesse sentido, que o estudo é de natureza qualitativa e a abordagem dos dados apresentada possui cunho interpretativo.

Sobre o histórico de sua criação, que justifica, de certo modo, a escolha para análise dessa rede, enfatiza-se que, em 1998, um grupo de professores de diferentes Instituições de Ensino Superior do Rio Grande do Sul iniciou discussões, aceitando o 
desafio de construir uma caminhada coletiva (RIES, 2020). Já em 2001, a caminho da consolidação da rede, foi realizado um simpósio internacional, reunindo várias instituições e estados brasileiros. Os precursores da rede foram: a Pontifícia Universidade Católica do Rio Grande do Sul (PUCRS), a Universidade do Vale do Rio dos Sinos (UNISINOS), a Universidade Federal do Rio Grande do Sul (UFRGS) e a Universidade Federal de Santa Maria (UFSM).

No encontro, face à necessidade da articulação sistemática dos investigadores, professores e discentes envolvidos com Educação Superior, um grupo de representantes de diferentes instituições, responsabilizaram-se pela elaboração de uma proposta de articulação. Buscava-se configurar a Rede Sulbrasileira de Investigadores de Educação Superior (RIES, 2020).

A partir disso, inicia-se um trabalho árduo de concretização de eventos anuais para as reflexões pertinentes à temática. A rede foi instituída e, desde então, vem contribuindo com estudos e investigações que busca a cooperação e o compromisso social dos pesquisadores na construção da Educação Superior e da Pedagogia Universitária como área de conhecimento e de prática profissional (RIES, 2020). Em 2005, foi escolhida como Núcleo de Excelência em Ciência, Tecnologia e Inovação do CNPq e da Fundação de Amparo à Pesquisa do Estado do Rio Grande do Sul (FAPERGS). Em 2014, reconhecida novamente, recebeu o projeto Programa de Apoio a Núcleos de Excelência (PRONEX).

Nesse contexto de avanço, em 2007, a RIES foi selecionada como Observatório de Educação: "Indicadores de Qualidade para a Educação Superior Brasileira" da CAPES e do Instituto Nacional de Pesquisas Educacionais Anísio Teixeira (INEP) (RIES 2020).

Nessa caminhada de consolidar o campo da Educação Superior, tem se destacado na publicação de enciclopédias: Enciclopédia de Pedagogia Universitária, Glossário, Enciclopédia de Educação Superior para os países de língua portuguesa (CPLP). E, a ser lançada ainda em 2020, a Enciclopédia Brasileira de Educação Superior (EBES).

Para reflexão sistemática sobre a rede, realizou-se uma pesquisa documental tendo como fonte os currículos dos membros chave, presentes desde o início de sua criação. O recorte foi a apreciação, a partir de 1999, das pesquisadoras que iniciaram a RIES e que a alimentam, a saber: Marília Costa Morosini, da PUCRS (coordenadora), Maria Estela Dal Pai Franco e Denise Balarine Cavalheiro Leite, da UFRGS, Maria Isabel da Cunha, da UNISINOS, Silvia Maria de Aguiar Isaia, e, mais recentemente, Dóris Pires Vargas Bolzan, ambas da UFSM.

É importante esclarecer que cada pesquisadora chave já possuía um grupo em suas instituições de origem, além de perfis consolidados de desenvolvimento de investigações no campo da Educação Superior. Desse modo, a RIES é uma rede que congrega metaredes de pesquisa.

Dos inúmeros dados possíveis de serem observados, optou-se por fazer uma representação da RIES a partir de 1999, sendo este o início de todo o processo de construção da rede, tomando por base o total de artigos por coautor, intitulados na plataforma lattes como indicadores de produção. A tabela a seguir exprime os 
resultados encontrados com o critério de primeira, segunda e terceira maior quantidade de produção em coautoria.

Tabela 3 - Membros chaves da RIES e quantitativo de artigos com pesquisadores com maior incidência a partir de 1999

\begin{tabular}{l|l|l|l|l|l|l}
\hline & \multicolumn{2}{|c|}{$\begin{array}{c}\text { Primeira maior } \\
\text { quantidade de co- } \\
\text { autoria }\end{array}$} & \multicolumn{2}{c|}{$\begin{array}{c}\text { Segunda maior } \\
\text { quantidade de co- } \\
\text { autoria }\end{array}$} & \multicolumn{2}{c}{$\begin{array}{c}\text { Terceira maior } \\
\text { quantidade de co- } \\
\text { autoria }\end{array}$} \\
\hline Pesquisadoras & Autor(a) & Quantidade & Autor(a) & Quantidade & Autor(a) & Quantidade \\
\hline D. LEITE & Campos & 14 & Genro & 8 & Loréa & 8 \\
\hline D. BOLZAN & Isaia & 15 & Powaczuk & 8 & Fighera & 4 \\
\hline M. FRANCO & Morosini & 14 & Nez & 3 & Longhi & 3 \\
\hline M. I. CUNHA & Zanchet & 6 & Leite & 3 & Pedroso & 2 \\
\hline $\begin{array}{l}\text { M. } \\
\text { MOROSINI }\end{array}$ & Franco & 16 & Felicetti & 13 & Cabrera & 5 \\
\hline $\begin{array}{l}\text { S. M. A. } \\
\text { ISAIA }\end{array}$ & Bolzan & 13 & Maciel & 7 & Bisognin & 4 \\
\hline
\end{tabular}

Fonte: Lattes (2019).

A título de esclarecimento, destaca-se que a coleta no lattes foi executada em dezembro de 2019. Sendo possível que os currículos dos membros da rede não estivessem totalmente atualizados, e isso pode trazer divergências com relação aos totais e indicadores de produção. Ressalta-se ainda que a tabela 3 ilustra uma parte do panorama geral da produção de artigos em coautoria, que, por ter grande dimensão, não foi possível trazer neste estudo.

Valendo-se das informações descritas na tabela 3, exprime-se a importância da vivência de participação em redes para o processo formativo dos pesquisadores. Para Baranzeli e Morosini (2018), isso significa dizer que as redes possibilitam compartilhar e elevar padrões teóricos, metodológicos e técnicos.

Observa-se que, entre as pesquisadoras membros da rede, há produção coletiva, nesse critério de maior quantidade de publicações em coautoria, que podem ser livros/capítulos ou periódicos, conforme as indicações em itálico (Franco - 16; Morosini - 14; Isaia 15; Bolzan 13 e Leite - 3). Há uma forte tendência de produção e socialização do conhecimento nacional e internacionalmente, indicando a realização de pesquisas compartilhadas ao invés do trabalho individual.

Desse modo, o pesquisador lida com elementos necessários para o seu desempenho numa sociedade em constante mudança, entre as quais estão o acesso e a produção do conhecimento. Para a formação dos pesquisadores, as redes são determinantes, assim como para o incremento e incentivo dos grupos. Para Franco (2000), forja-se a identidade do professor como partícipe da comunidade do conhecimento, empenhado na busca da dimensão valorativa, relevante para a formação da sociedade da qual faz parte.

A imagem 1 identifica quem foram os colaboradores para a escrita de artigos científicos e publicações em livros e/ou periódicos. É importante esclarecer que a representação foi respaldada pelo currículo atualizado até o mês de dezembro de 2019, quando foi realizado o levantamento. 
Imagem 1 - Membros chaves da RIES e parcerias de artigos com pesquisadores com maior incidência de publicações a partir de 1999

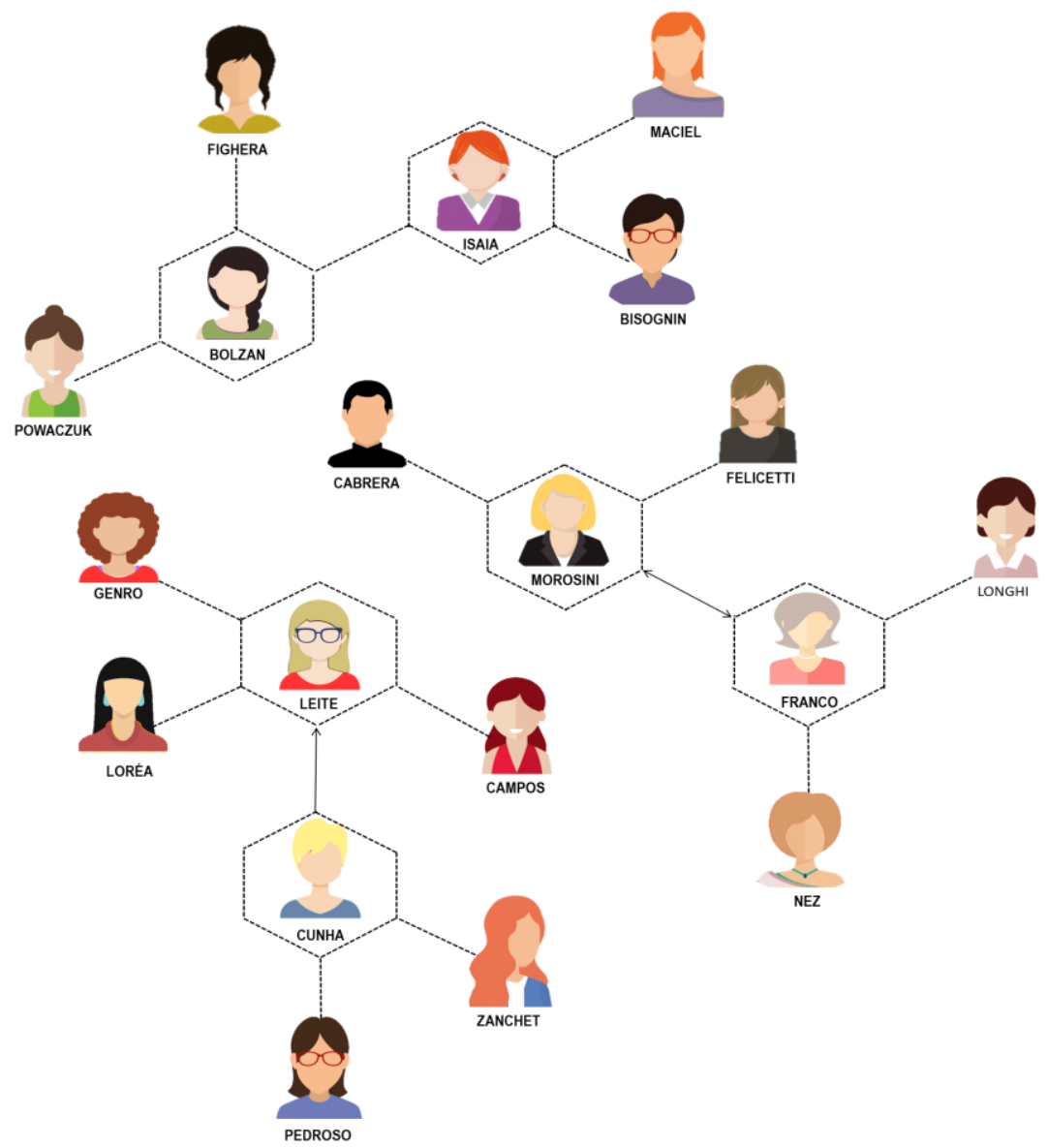

Arte elaborada por: Marina Santos Graziano de Oliveira.

Fonte: Lattes (2019).

$\mathrm{Na}$ imagem, as pesquisadoras fundadoras da rede estão identificadas com um hexágono, o que não se vê nas outras. Considera-se, com esses dados, que a pesquisa é um empreendimento que pode ser realizado com parcerias (redes), nas quais são constituídas as interlocuções no espaço territorial expressivo e com universidades diversas.

Destarte, tem-se, nessa figura, a representação de várias instituições envolvidas: Universidade de Passo Fundo (UPF), Universidade Federal do Mato Grosso (UFMT), Universidade do Estado de Mato Grosso, Universidade La Salle, (UNILASALLE), Universidade Federal de Pelotas (UFPEL), Universidade Franciscana, entre outras. 
Além dessas, há duas instituições internacionais nesse período: Universidade de Maryland e Universidade de Buenos Aires. Todavia, é válido comentar que esse resultado é expressivo apenas das líderes que criaram a rede, numa data temporal, que, atualmente, é composta de inúmeros pesquisadores, espalhados em outros espaços nacionais e internacionais com parcerias profícuas.

A existência desses espaços coletivos é impulsionadora da pesquisa no lócus das universidades. Assim, enfatiza-se que alguns grupos/redes de pesquisa são uma realidade materializada, possibilitando a construção do conhecimento institucionalizado e a divulgação das atividades, que buscam excelência ao longo dos anos.

Os dados analisados identificam que a RIES é uma rede consolidada no cenário nacional e internacional. Prova disso, é a quantidade de artigos publicados em revistas internacionais que podem ser verificados no lattes de cada pesquisador. Nesse sentido, cada grupo/rede equivale a uma posição, sendo que aquele espaço ocupado aumenta o campo de articulação.

Para Bourdieu (1974), o dominante será aquele que ocupa um lugar na estrutura e que age, favoravelmente, às suas ações. Hey (2008) explicita que o pólo dominante é aquele que determina as posições: o político e o prestígio intelectual. Isso permite a circulação dos agentes nos espaços que propiciam sua integração na academia e contribui decisivamente para a excelência acadêmica.

Nessa direção, a potencialização dos grupos decorre da perspectiva de que a produção de conhecimentos é um trabalho coletivo, realizado em redes, conforme perceptível na organização da RIES. Isso significa dizer que as redes integram os projetos e auxiliam no aprofundamento das relações entre os pesquisadores e as instituições.

Bourdieu (2004) esclarece que as representações dos agentes também variam segundo seu lugar e a associação dos seus interesses. O habitus é gerador de um sentido de pertencimento a um espaço. No caso aqui, trata-se de um grupo/rede de pesquisa, que se reporta ao lugar de pesquisador. Dessa forma, "[...] implica não apenas um sense of one's place, mas também um sense of other's place" (p. 158).

Enfim, expõe-se que uma rede de pesquisa marca a ruptura com uma visão estruturalista e burocrática das universidades enquanto organização, colocando em evidência uma abordagem interdisciplinar, baseada nas conexões que alavancam as atividades de ensino, pesquisa e extensão.

\section{CONSIDERAÇÕES FINAIS}

Partindo do aporte teórico proporcionado pelo estado de conhecimento, mostrou-se imprescindível um momento sintético para fechamento das reflexões que podem referendar que o Brasil representa no cenário latino-americano um sistema nacional academicamente sólido, com respeitabilidade e reconhecimento na produção e socialização do conhecimento.

As redes auxiliam na pesquisa nacional e internacional, através da interação entre os investigadores e interlocução entre os pares. Acredita-se que a consolidação das redes faz parte do processo de internacionalização, pois, segundo Baranzeli e Morosini (2018), elas promovem a integração que leva em conta não apenas conhecimentos globais, mas também aspectos interculturais, locais e regionais. Ao buscar conhecer outras interpretações, teorias, contextos, realidades, vivências e 
experiências, os pesquisadores que se articulam em redes acabam realizando uma experiência formativa diferenciada.

Para isso, a vitalidade acadêmica se reforça nas universidades que tem como uma de suas garantias de existência a atividade de produção da pesquisa no espaço da Pós-graduação. É oportuno enfatizar a distribuição de infraestruturas e fluxos gerados pelas atividades intensivas de produção do conhecimento em algumas regiões brasileiras, que se destacam no contexto atual da internacionalização.

Para finalizar as reflexões deste estudo, evidencia-se que os grupos podem proporcionar excelência à Educação Superior, e os maiores beneficiados são os acadêmicos, que tem ressonância na sociedade. A melhoria se dá, efetivamente, no fortalecimento na socialização do conhecimento produzido, assim como na possibilidade de construção de novas parcerias, pois que privilegiam a integração das redes.

Assim, este estudo analítico das RIES aponta que a saída possível é fortalecer e propulsionar as redes, bem como concentrar-se em esforços de produção em pesquisas coletivas e interinstitucionais de excelência acadêmica. Essa alternativa traz grandes desafios, atrelados a questão da interdisciplinaridade dos projetos e impacta diretamente na carreira docente. Para isso, é preciso romper o isolacionismo do trabalho intelectual, que favorece o narcisismo que permeia as relações paradoxais da sociedade contemporânea.

É conclusiva a afirmação de que a participação em redes de pesquisa potencializa a produção do conhecimento, além de gerar um acréscimo na qualidade das investigações realizadas, intensificando a experiência formativa dos pesquisadores seniores e da nova geração. Também foi possível compreender que o conhecimento gerado pelas redes de pesquisa tem maior alcance quando produzidos coletivamente, pois atingem maior espaço quando socializados.

Artigo recebido em: 29/01/2020

Aprovado para publicação em: 17/05/2020

\section{RESEARCH NETWORKS AS AN INTEGRATING PROPOSAL FOR THE INTERNATIONALIZATION OF} KNOWLEDGE IN EMERGING CONTEXTS

ABSTRACT: This study discusses the relationship between research networks and the construction of knowledge and the training of researchers, with emphasis on internationalization. Methodologically, it started from a state of knowledge, and a documentary research (lattes) was carried out of the key members of the Sulbrasileira Network of Higher Education Researchers (RIES). Data analysis was based on a critical approach to content. The statement that participation in research networks enhances the production of knowledge, in addition to generating an increase in the quality of investigations, intensifying the training experience of researchers is conclusive. It was also possible to understand that the knowledge generated by the networks has greater reach when produced collectively and disseminated in the metaredes.

KEYWORDS: Higher Education. knowledge production. Research networks. Internationalization. 
REDES DE INVESTIGACIÓN COMO PROPUESTA INTEGRADORA PARA LA INTERNACIONALIZACIÓN DEL CONOCIMIENTO EN CONTEXTOS EMERGENTES

RESUMEN: Este estudio discute la relación entre las redes de investigación y la construcción del conocimiento y la formación de investigadores, con énfasis en la internacionalización. Metodológicamente, partió de un estado de conocimiento, y se llevó a cabo una investigación documental (lattes) de los miembros clave de la Red de Investigadores de Educación Superior de Sulbrasileira (RIES). El análisis de datos se basó en un enfoque crítico del contenido. La afirmación de que la participación en redes de investigación mejora la producción de conocimiento, además de generar un aumento en la calidad de las investigaciones, intensificando la experiencia de capacitación de los investigadores es concluyente. También fue posible comprender que el conocimiento generado por las redes tiene un mayor alcance cuando se produce colectivamente y se difunde en los metaredes.

PALABRAS CLAVE: Educación superior. Producción de conocimiento. Redes de investigación. Internacionalización.

\section{REFERÊNCIAS}

BARANZELI, C.; MOROSINI, M. C. Internacionalização em casa - IAC e redes investigativas: possibilidades segundo docentes brasileiros. FRANCO, S.; FRANCO, M. E. D. P.; LEITE, D. B. C. (orgs.). Educação superior e conhecimento no centenário da reforma de Córdoba: novos olhares em contextos emergentes. Porto Alegre: EDIPUCRS, 2018.

BARDIN, L. Análise de conteúdo. Lisboa: Edições 70, 2009.

BIANCHETTI, L.; MACHADO, A. M. N. “Reféns da produtividade" sobre produção do conhecimento, saúde dos pesquisadores e intensificação do trabalho na pósgraduação. Disponível em: http://www.anped.org.br/reunioes/30ra/trabalhos/GT093503--Int.pdf. Acesso em: 02 set. 2012.

BOGDAN, R; BIKLEN, S. Investigação qualitativa em educação. Porto: Porto, 1994.

BOURDIEU, P. A economia das trocas simbólicas. São Paulo: Perspectiva, 1974.

BOURDIEU, P. Coisas ditas. Trad. Cássia R. da Silveira e Denise Moreno Pegorim. São Paulo: Brasiliense. 2004.

DIDRIKSSON, A. Educación superior y sociedad del conocimiento en América Latina y el Caribe, desde la perspectiva de la Conferencia Mundial de la UNESCO. TUNNERMANN B, C. La educación superior en América Latina y el Caribe: diez años despues de la Conferencia Mundial. Colômbia: IESALC/UNESCO, 2008. Disponível em: http://www.iesalc.unesco.org.ve/index.php?option=com fabrik\&c=form\&view=details\& ttemid=840\&fabrik=10\&rowid=5\&tableid=10\&lang=es. Acesso em: 12 ago. 2011. 
DIRETÓRIO de grupos de pesquisa no Brasil. Disponível em: http://dgp.cnpq.br. Acesso em: 15 jul. 2018.

ENLACES. Disponível em: http://iesalc.unesco.org.ve/index.php?option=com content \&view=frontpage\&ltemid $=3$ 03. Acesso em: 03 nov. 2012.

FRANCO, M. E. D. P. Construção de conhecimento acerca da qualidade na gestão da educação superior. MOROSINI, M. C. (org.). Qualidade na educação superior: reflexões e práticas investigativas. v. 3. Porto Alegre: Edipucrs, 2011.

FRANCO, M. E. D. P. Comunidade de conhecimento, pesquisa e formação do professor do ensino superior. MOROSINI, M. C. (org.). Professor do ensino superior: identidade, docência e formação. Brasília: Instituto Nacional de Estudos e Pesquisas Educacionais (INEP), 2000.

FRANCO, M. E. D. P.; MOROSINI, M. C. (orgs.) Redes acadêmicas e produção do conhecimento em educação superior. Brasília: INEP, 2001.

HEY, A. P. Esboço de uma sociologia do campo acadêmico. São Carlos: EdUFSCar, 2008.

LEITE, D. Avaliação institucional participativa e a universidade socialmente empreendedora. Avaliação, Sorocaba, v. 10. n. 1. mar. 2005.

LIMA, M. C.; CONTEL, F. B. Internacionalização da educação superior: nações ativas, nações passivas e a geopolítica do conhecimento. São Paulo: Alameda, 2011.

LIMA, E. G. S.; LEITE, D. Influências da avaliação no conhecimento produzido pelos pesquisadores em redes de pesquisa. LEITE, D.; LIMA, E. G. S. (orgs). Conhecimento, avaliação e redes de colaboração: produção e produtividade na universidade. Porto Alegre: Sulina, 2012.

MENEZES, L. C. Universidade sitiada: a ameaça da liquidação da universidade brasileira. São Paulo: Fundação Perseu Abramo, 2000.

MOCELIN, D. G.; FRANCO, M. E. D. P. Grupos de pesquisa. MOROSINI, M. C. (ed.). Enciclopédia de pedagogia universitária: glossário. v. 2. Brasília: Inep/RIES, 2006.

MOROSINI, M. C. Apresentação. Dossiê: internacionalização da educação superior. Educação, Porto Alegre, v. 40, n. 3, set./dez. 2017. 
MOROSINI, M. C. Estado do conhecimento sobre internacionalização da educação superior: conceitos e práticas. Educar, Curitiba, n. 28, 2006.

MOROSINI, M. C. Internacionalização da Educação Superior em contextos emergentes: uma análise das perspectivas internacional, nacional e institucional. Educação superior em contextos emergentes. FRANCO, M. E. D. P.; ZITKOSKI, J.; KIELING, S. R. (orgs.) Porto Alegre: EdiPUCRS, 2016.

NEZ, E. Em busca da consolidação da pesquisa e da pós-graduação numa universidade estadual: a construção de redes de pesquisa. 2014. s.n/f. Tese (Doutorado em Educação) - Universidade Federal do Rio Grande do Sul, Porto Alegre, 2014.

NEZ, E. Fluxos de cooperação acadêmica para a internacionalização. MOROSINI, M. C.

(org.) Guia para a internacionalização universitária. Porto Alegre: EDIPUCRS, 2019.

PLATAFORMA LATTES. Disponível em: http://lattes.cnpq.br/. Acesso em: 5 dez. 2019.

RAMOS, M. G. Pesquisa na universidade e espaços de produção: sinalizando caminhos. FRANCO, M. E. D. P.; LONGHI, S. M.; RAMOS, M. G. (orgs.). Universidade e pesquisa: espaços de produção do conhecimento. Pelotas: UFPel, 2009.

RIES. Disponível em: http://www.pucrs.br/humanidades/ries/\#historico. Acesso em: 12 jan. 2020.

SANTOS, M. Natureza do espaço: técnica e tempo. Razão e emoção. 4. ed. São Paulo: USP, 2006.

SEBASTIÁN, J. La internacionalización de las universidades como estrategia para el desarrollo institucional. Innovación educativa, Ciudad de México, v. 5, n. 26, mayo-jun. 2005.

SEVERINO, A. J. Metodologia do trabalho científico. 23. ed. São Paulo: Cortez, 2010.

TORRES, D. R. As redes universitárias e a cooperação acadêmica solidária através do ENLACES. Disponível em:

http://www.iesalc.unesco.org.ve/index.php?option=com_content\&view=article\&id=236 2\%3Alas-redes-universitarias-y-la-cooperacion-academica-solidaria-a-traves-delenlaces\&catid=126\%3Anoticias-pagina-nueva\&ltemid=712\&lang=br. Acesso em: 03 nov. 2011.

UNESCO. Educação superior: reforma, mudança e internacionalização. Anais da

Segunda Reunião dos Parceiros da Educação Superior. Brasília/Paris: UNESCO, 2003. 
Marília Costa MorosinI: Possui licenciatura e bacharelado em Ciências Sociais (1970), mestrado em Sociologia Educacional (1975) e doutorado em Educação pela UFRGS (1990) e pós-doutorado no LILLAS/Universidade do Texas (2002/2003). Professora aposentada da UFRGS e professora titular da PUCRS.

Orcid: https://orcid.org/0000-0002-2433-5783

E-mail: marilia.morosini@pucrs.br

EgesLaIne de Nez: Possui graduação em Pedagogia pela Universidade Estadual do Oeste do Paraná e Mestrado em Educação pela Universidade Estadual de Ponta Grossa. Doutora em Educação pela Universidade Federal do Rio Grande do Sul (UFRGS). Pós Doutora pela PUCRS. Atualmente é professora da Universidade Federal de Mato Grosso (UFMT), Campus Universitário do Araquaia - Barra do Garças/MT.

Orcid: https://orcid.org/0000-0002-0316-0080

E-mail:e.denez@yahoo.com.br

Este periódico utiliza a licença Creative Commons Attribution 3.0, para periódicos de acesso aberto (Open Archives Iniciative - OAI). 